\title{
HPLC methods for quality control of Moringa oleifera extract using isothiocyanates and astragalin as bioactive markers
}

\author{
Jinutda Engsuwan $^{\mathrm{a}, \mathrm{b}}$, Neti Waranuch ${ }^{\mathrm{b}}$, Nanteetip Limpeanchob ${ }^{\mathrm{c}}$, Kornkanok Ingkaninan ${ }^{\mathrm{a}, \mathrm{b}, *}$ \\ a Bioscreening Unit, Department of Pharmaceutical Chemistry and Pharmacognosy, \\ Faculty of Pharmaceutical Sciences and Center of Excellence for Innovation in Chemistry, \\ Naresuan University, Phitsanulok 65000 Thailand \\ b Cosmetics and Natural Products Research Center, Faculty of Pharmaceutical Sciences, \\ Naresuan University, Phitsanulok 65000 Thailand \\ c Department of Pharmacy Practice, Faculty of Pharmaceutical Sciences, Naresuan University, \\ Phitsanulok 65000 Thailand
}

*Corresponding author, e-mail: k_ingkaninan@yahoo.com

Received 27 Dec 2016

Accepted 22 Jun 2017

\begin{abstract}
Herbal extracts are gaining widespread acceptance as ingredients in cosmetic and health products. Moringa oleifera Lam. is an interesting candidate as it has multiple biological properties. However, methods for quality control of the use of $M$. oleifera are still required. This study proposes the use of isothiocyanate compounds and astragalin as chemical markers to standardize $M$. oleifera extracts. Both of these compounds are known to have anti-inflammation properties, and astragalin is also reported to have antioxidant properties. The HPLC-based cyclocondensation method was further developed and validated specifically for quantitative analysis of the isothiocyanate compounds in the M. oleifera extracts, and the concentration of astragalin in the $M$. oleifera extracts was determined by the HPLC method. Both methods gave acceptable linearity, accuracy, and precision with the limit of detection of $0.13 \mu \mathrm{g} / \mathrm{ml}$ for total isothiocyanate and $0.10 \mu \mathrm{g} / \mathrm{ml}$ for astragalin. The uses of the methods were demonstrated in the analyses of the components in the extracts taken variously from the leaves, immature seeds, mature seeds, petioles, and pods of the $M$. oleifera tree. Our results suggest that the methods developed could be used in the quality control of $M$. oleifera extracts to develop cosmetic and natural health products.
\end{abstract}

KEYWORDS: anti-inflammation, antioxidant, chemical analysis, cyclocondensation

\section{INTRODUCTION}

Moringa oleifera Lam. (Moringaceae family) is a plant commonly found in several tropical and subtropical countries. Traditionally, M. oleifera has been used for its medicinal benefits, including antiinflammation $^{1-3}$, anti-oxidation ${ }^{4-6}$, anti-bacterial, and anti-fungal ${ }^{7-9}$ properties, wound healing $^{10-12}$, and skin revitalization ${ }^{13}$. Currently, many cosmetics and natural health products use $M$. oleifera extracts as an active ingredient. This situation therefore deserves more analysis and understanding of the $M$. oleifera, as evidenced by the call of the Dietary Supplements and Herbal Medicines (DSHM) Nomenclature Subcommittee, the U.S. Pharmacopeial Convention (USP) for a Priority New Dietary Supplement Monograph on the subject (www.usp. org).

The bioactive constituents of $M$. oleifera related to cosmeceutical and medicinal actions are astragalin, a major flavonoid from the leaves, and isothiocyanate glycosides (Fig. 1). Astragalin has been shown to exhibit anti-skin inflammation action in mice $^{14}$, an effect that may relate to the inhibition of nuclear factor-kappa B (NF- $\kappa \mathrm{B})$ signalling pathway ${ }^{15-18}$. Astragalin is also known to have antioxidant properties ${ }^{19-21}$. Isothiocyanate glycosides, found in leaves, seeds, and pods, exhibit strong antiinflammatory activity by regulating the production of nitric oxide (NO), inducible NO synthase (iNOS), and cytokines of macrophages in vitro ${ }^{22-25}$.

In the present study, we propose to use astragalin and isothiocyanates as chemical markers for quality control and standardization of $M$. oleifera extract. A procedure for the quality control of $M$. oleifera leaves has been extensively described in the Ayurvedic Pharmacopoeia of India. However, the chemical analysis described in that monograph 

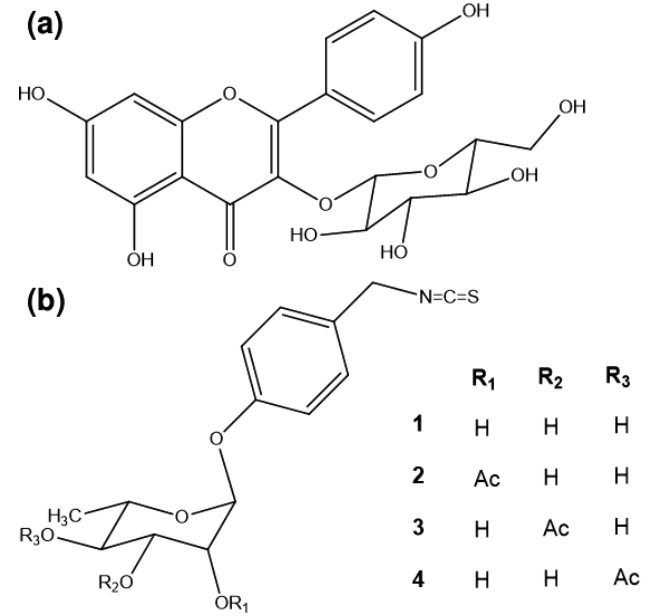

Fig. 1 Structure of (a) astragalin and (b) Moringa oleifera isothiocyanates (1-4): (1) 4-[( $\alpha$-L-rhamnosyloxy) benzyl] isothiocyanate, (2) 4-[(2'-O-acetyl- $\alpha$-L-rhamnosyloxy)benzyl] isothiocyanate, (3) 4-[( $3^{\prime}-O$-acetyl- $\alpha$-L-rhamnosyloxy)benzyl $]$ isothiocyanate, (4) 4-[(4'-O-acetyl- $\alpha-\mathrm{L}-$ rhamnosyloxy)benzyl] isothiocyanate.

was conducted via thin-layer chromatography system without any chemical markers ${ }^{26}$. Astragalin has been used as a chemical marker for quality control of $M$. oleifera using the high performance liquid chromatography (HPLC) method in the Malaysian Herbal Monograph but the run time is quite long (55 min per sample) ${ }^{27}$. In this study, we develop and validate the HPLC-condensation method for quantitative analysis of total isothiocyanate compounds and the HPLC method for the quantitative analysis of astragalin in M. oleifera extracts. The extracts of the leaves, immature seeds, mature seeds, pods, and petioles from $M$. oleifera were determined for the presence of these compounds using both proven methods.

\section{MATERIALS AND METHODS}

\section{Chemicals and reagents}

Standard compounds of astragalin and phenethyl isothiocyanate were purchased from Sigma-Aldrich (Steinheim, Germany). 1,2-benzenedithiol was acquired from Tokyo Chemical Industry (Tokyo, Japan). All solvents used were of HPLC grade and were obtained from RCI Labscan (Bangkok, Thailand).

\section{Plant materials}

Leaves, immature seeds, mature seeds, pods, and petioles of M. oleifera were collected from Phitsa- nulok Province, Thailand. After cleaning, the plant samples were dried in a hot air oven at $50^{\circ} \mathrm{C}$. The dried samples were ground into coarse powder. The voucher specimen was kept at Faculty of Science, Naresuan University (Phitsanulok, Thailand). The plant was identified by Dr Pranee Nangngam.

\section{Plant extractions}

The rough powdered $M$. oleifera leaves were extracted in three different solvents: water, 50\% ethanol, and $95 \%$ ethanol. For extraction by water, the powder was infused with water at $60-70^{\circ} \mathrm{C}$, and shaken for $45 \mathrm{~min}$. The resulting extract was filtered through filter paper, and the water was removed by freeze drying. For the $50 \%$ ethanol extract, the powder was macerated with $50 \%$ ethanol for $48 \mathrm{~h}$ while shaking and then filtered through filter paper. The ethanol was then evaporated by a rotary evaporator. The residual water was then removed by freeze drying. For the $95 \%$ ethanol extract, the powder was macerated with $95 \%$ ethanol for $48 \mathrm{~h}$ while shaking and then filtered through filter paper. The ethanol was then evaporated using a rotary evaporator. The other plant parts (immature seeds, mature seeds, pods, and petioles) were coarsely powdered. The powder was then macerated in $50 \%$ ethanol to obtain the crude extracts by the methods described earlier. After extraction, the crude extracts were weighed and stored in a freezer $\left(-20^{\circ} \mathrm{C}\right)$ for further use.

\section{Plant extract solutions}

Stock solutions of $M$. oleifera extract were prepared at $10 \mathrm{mg} / \mathrm{ml}$. The water extracts and $50 \%$ ethanol extracts were dissolved in distilled water, and the 95\% ethanol extracts were dissolved in ethanol. The stock solutions of the extracts were then diluted to $1 \mathrm{mg} / \mathrm{ml}$ in the mobile phase before HPLC analyses.

\section{HPLC-based cyclocondensation method to determine total isothiocyanates}

Standard stock solutions of phenethyl isothiocyanate were prepared by dissolving the substances in methanol to a final concentration of $1 \mathrm{mg} / \mathrm{ml}$. The standard working solutions were made by diluting the stock solutions with mobile phase.

The cyclocondensation assay method was modified from the previous report ${ }^{28,29}$. Briefly, in a 5-ml glass vial, $0.25 \mathrm{ml}$ of each phenethyl isothiocyanate sample was mixed with $0.25 \mathrm{ml}$ of $100 \mathrm{mM} \mathrm{K}_{3} \mathrm{PO}_{4}$ buffer (pH 8.5), $0.5 \mathrm{ml}$ of $10 \mathrm{mM}$ 1,2-benzenedithiol in methanol. The reaction mixture was incubated 
for $2 \mathrm{~h}$ at $65^{\circ} \mathrm{C}$, and then cooled to room temperature. The mixture was filtered through $0.45 \mu \mathrm{m}$ nylon membrane. A $0.1 \mathrm{ml}$ aliquot of the mixture was injected into the HPLC system for analysis of the isothiocyanates content.

The HPLC system used in the analysis consisted of Shimadzu LC-2OAT pumps, DGU-20A5 degasser SPD-M10Avp diode array detector, and Phenomenex Gemini $5 \mu \mathrm{m}$ C18 column. The isocratic mobile phase was methanol: water $(4: 1 \mathrm{v} / \mathrm{v})$, at a flow rate of $1.2 \mathrm{ml} / \mathrm{min}$. The eluates were monitored at $365 \mathrm{~nm}$. Each sample was eluted for a total of $7 \mathrm{~min}$.

\section{HPLC method for determination of astragalin}

Standard stock solutions of astragalin were prepared by dissolving the substances in methanol to a final concentration of $1 \mathrm{mg} / \mathrm{ml}$. The standard working solutions were made by diluting the stock solutions with the HPLC mobile phase.

The accuracy was evaluated by performing the recovery study. Solutions of three known concentrations of standard compound were added to $100 \mu \mathrm{g} / \mathrm{ml}$ of $M$. oleifera leaf extract samples. The recovery of each standard concentration from the spiked samples was calculated.

The method was modified from the previous study $^{30}$. The HPLC system configuration as mentioned above was used together with Phenomenex Luna $5 \mu \mathrm{m}$ C18 column. The isocratic mobile phase was $0.1 \%$ acetate buffer: acetonitrile $(3: 1 \mathrm{v} / \mathrm{v})$, pH 4.5 at a flow rate of $1 \mathrm{ml} / \mathrm{min}$. The eluates were monitored at $267 \mathrm{~nm}$. The total run time was $12 \mathrm{~min}$

\section{Method validation}

Both methods were validated for range of linearity of the calibration curve, precision, accuracy, LOD, and LOQ values.

The calibration curves were plotted by peak areas and the concentrations of each standard. The stock standard solutions were diluted to 6 different concentrations. The linear regression equations were $y=a x \pm b$, where $x$ was the concentration and $y$ was the peak area of each standard. The linearity was verified by linear regression $\left(R^{2}\right)$.

The precision was assessed by repeated injection at each of 3 concentrations in calibration curve. The intra-day precision was determined by 5 replicates for a day, and the inter-day precision was determined by 5 replicates for each of 3 days. The precision was assessed by calculating the relative standard deviation (RSD).
Limit of detection (LOD) was defined as the lowest concentration which can still be detected by the analysis method but does not have an accurate value. This was determined by the signal-to-noise ratio of 3:1. Limit of quantification (LOQ) was defined as the lowest sample concentration which can still be quantitatively detected with accuracy and precision. It was determined by the signal-tonoise ratio of 10:1.

\section{Determination of astragalin and total isothiocyanates in M. oleifera leaf extracts}

Total isothiocyanates and astragalin in various $M$. oleifera extract samples were determined using the validated HPLC methods.

\section{RESULTS AND DISCUSSION}

\section{Validation of HPLC method for determination of astragalin and total isothiocyanates}

The cyclocondensation assay depends on the carbon atom of the $-\mathrm{N}=\mathrm{C}=\mathrm{S}$ group of the isothiocyanate compound reacting with the thiol groups of 1,2-benzenedithiol to form 1,3-benzodithiole-2-thione and the corresponding amine (Fig. 2).

The product of the reaction was determined by HPLC. The typical chromatograms of 1,3-benzodithiole-2-thione from cyclocondensation of phenethyl isothiocyanate standard is shown in Fig. 3a. The retention time of 1,3-benzodithiole-2-thione was $4.13 \mathrm{~min}$. The amount of total thiocyanates in the samples determined was reported as equivalent to phenethyl isothiocyanate. For the analysis of another active constituent, astragalin, an HPLC method was also used. A typical chromatogram of astragalin standard is shown in Fig. 4a. Astragalin was eluted at $5.41 \mathrm{~min}$. Linearity was achieved in the range $0.5-16 \mu \mathrm{g} / \mathrm{ml}$ for both methods. The calibration curves were linear with excellent correlation coefficients $\left(R^{2}>0.999\right)$. The regression equations

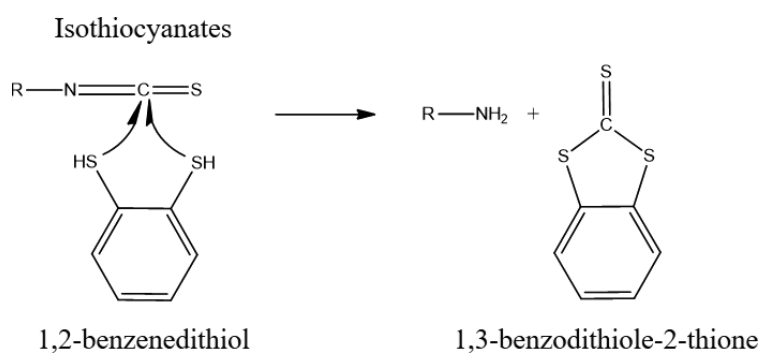

Fig. 2 Reaction of isothiocyanates with 1,2-benzenedithiol. 


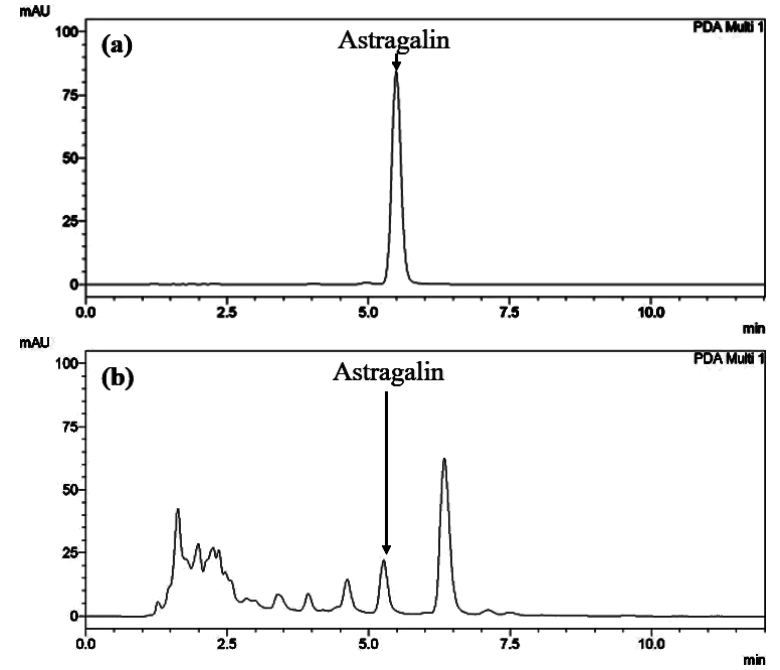

Fig. 3 Typical HPLC chromatograms showing reaction products from cyclocondensation of (a) phenethyl isothiocyanate standard (16 $\mu \mathrm{g} / \mathrm{ml})$ and (b) $50 \%$ ethanol extract of $M$. oleifera leaves $(1 \mathrm{mg} / \mathrm{ml})$.

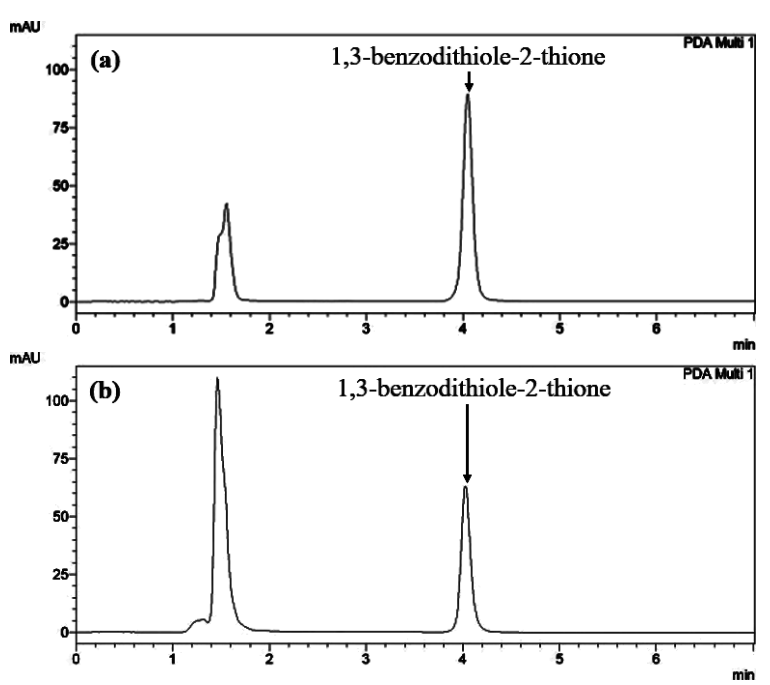

Fig. 4 Typical HPLC chromatograms showing (a) astragalin standard (16 $\mu \mathrm{g} / \mathrm{ml})$ and (b) $50 \%$ ethanol extract of $M$. oleifera leaves $(1 \mathrm{mg} / \mathrm{ml})$.

were $y=43028 x+7966.5$ for phenethyl isothiocyanate and $y=50495 x-723.02$ for astragalin. The minimum concentration levels which can be detected (LOD) and quantified (LOQ) in the analysis were found to be $0.13 \mu \mathrm{g} / \mathrm{ml}$ and $0.5 \mu \mathrm{g} / \mathrm{ml}$ for phenethyl isothiocyanate, $0.1 \mu \mathrm{g} / \mathrm{ml}$ and $0.5 \mu \mathrm{g} / \mathrm{ml}$ for astragalin, respectively. This indicated that both HPLC methods are properly sensitive for the quantification of these bioactive compounds. The RSD
Table 1 Linear range $(\mu \mathrm{g} / \mathrm{ml})$, linear equation, and linearity $\left(R^{2}\right)$ of total isothiocyanates and astragalin obtained from HPLC methods.

\begin{tabular}{lccc}
\hline Compound & Range & Linear equation & $R^{2}$ \\
\hline Isothiocyanates & $0.5-16$ & $y=43028 x+7966.5$ & 1.000 \\
Astragalin & $0.5-16$ & $y=50495 x-723.02$ & 0.999 \\
\hline
\end{tabular}

and recovery values were within acceptable ranges based on the AOAC Guidelines for Single Laboratory Validation of Chemical Methods (www.aoac.org). All method validation parameters are shown in Tables 1 and 2. These results demonstrated that both methods were reproducible with good accuracy and precision. System suitability parameters for isothiocyanates and astragalin demonstrated that the methods are suitable for determining these compounds in M. oleifera extracts.

\section{Determination of total isothiocyanates and astragalin in $M$. oleifera extracts}

To pinpoint $M$. oleifera extracts that had high amount of bioactive compounds, the HPLC methods were applied for determination of total isothiocyanates and astragalin contents in different extracts of leaves, immature seeds, mature seeds, pods, and petioles of $M$. oleifera. The representative chromatogram of reaction product from cyclocondensation of $M$. oleifera extract and the representative chromatogram of $M$. oleifera extract are shown in Figs. 3b and 4b, respectively. The extraction yields and the contents of total isothiocyanates and astragalin in different extracts are exhibited in Table 3. The extracts from $M$. oleifera leaves, extracted by $50 \%$ ethanol, had the highest extraction yield compared to those extracted with water and 95\% ethanol.

Although a quantitative analysis of isothiocyanate contents in $M$. oleifera leaf extract using liquid chromatography mass spectrometry has previously been reported, only compounds 1 and 4 were determined $^{25}$. Hence, our study is the first report on analyses of total isothiocyanate contents (compounds 1-4) in the extracts taken variously from the leaves, immature seeds, mature seeds, petioles, and pods of the M. oleifera tree. Isothiocyanates were detected in all extracts and ranged from $0.72-27.84 \mathrm{mg}$ of phenethyl isothiocyanate equivalent/g extract. In comparison with the other extracts, the mature seed extract had the highest amount of total isothiocyanates. The leaf extract prepared by $50 \%$ ethanol had a higher amount of 
Table 2 Precision, accuracy, LOD, and LOQ values of total isothiocyanates and astragalin obtained from HPLC methods.

\begin{tabular}{|c|c|c|c|c|c|c|}
\hline \multirow[t]{2}{*}{ Compound } & \multicolumn{2}{|c|}{ RSD (\%) } & \multicolumn{2}{|c|}{ Recovery (\%) } & \multirow{2}{*}{$\begin{array}{c}\text { LOD } \\
(\mu \mathrm{g} / \mathrm{ml})\end{array}$} & \multirow{2}{*}{$\begin{array}{c}\text { LOQ } \\
(\mu \mathrm{g} / \mathrm{ml})\end{array}$} \\
\hline & Intra-day $(n=5)$ & Inter-day $(n=15)$ & Intra-day $(n=3)$ & Inter-day $(n=9)$ & & \\
\hline Total isothiocyanates & $1.80-3.49$ & $5.22-5.67$ & 104.1-109.0 & $105.5-106.6$ & 0.13 & 0.5 \\
\hline Astragalin & $0.96-2.58$ & $0.70-3.17$ & $98.4-107.7$ & $104.8-108.2$ & 0.10 & 0.5 \\
\hline
\end{tabular}

Table 3 Extraction yields (\% w/w), total isothiocyanate ( $\mathrm{mg}$ of phenethyl isothiocyanate equivalent/g extract), and astragalin (mg/g extract) in various $M$. oleifera extracts.

\begin{tabular}{|c|c|c|c|c|c|c|c|}
\hline \multirow[t]{2}{*}{ Analysis } & \multirow{2}{*}{$\frac{\text { Water }}{\text { Leaves }}$} & \multirow{2}{*}{$\begin{array}{c}95 \% \text { Ethanol } \\
\text { Leaves }\end{array}$} & \multicolumn{5}{|c|}{$50 \%$ Ethanol } \\
\hline & & & Leaves & Immature seeds & Mature seeds & Pods & Petioles \\
\hline Extraction yield & 7.54 & 7.20 & 11.71 & 15.55 & 11.85 & 11.90 & 5.75 \\
\hline Isothiocyanates & $2.46 \pm 0.11$ & $0.72 \pm 0.10$ & $7.52 \pm 0.44$ & $13.9 \pm 1.0$ & $27.84 \pm 0.34$ & $7.22 \pm 0.80$ & $17.9 \pm 1.5$ \\
\hline Astragalin & $1.41 \pm 0.27$ & $6.88 \pm 0.91$ & $4.73 \pm 0.41$ & nd & nd & $<\mathrm{LOQ}$ & $1.90 \pm 0.33$ \\
\hline
\end{tabular}

Values are means \pm SD from triplicate experiments; nd: not detected.

total isothiocyanates than in the extracts by the other solvents. Nevertheless, the amount of total isothiocyanates in leaf extracts in our study was lower than in the extracts by water in the previous study. The variation may be possibly caused by the effect of different cultivated area and extraction process.

For the HPLC analyses of astragalin in $M$. oleifera extract, our method needed shorter run time than the previous methods. Astragalin was not detected in the immature seed and mature seed extracts and could not be quantified ( $<$ LOQ) in the pod extract. The 95\% ethanol extract of leaves had the highest amount of astragalin followed by the $50 \%$ ethanol extract of leaves. The amount of astragalin in the leaf extracts prepared by $95 \%$ ethanol and 50\% ethanol were higher than in those prepared in $70 \%$ ethanol extract in the previous study.

\section{CONCLUSIONS}

The two developed HPLC methods for the quantitative determination of anti-inflammatory and antioxidant compounds, total isothiocyanates, and astragalin in $M$. oleifera extracts are simple, rapid, precise, and accurate. Consequently, these methods can be used for quality control and standardization of $M$. oleifera raw materials, extracts, and finished products. The $50 \%$ ethanol extract of mature seeds had the highest content of total isothiocyanates without the presence of astragalin. The high content of total isothiocyanates and astragalin that was found in 50\% ethanol extract of leaves indicates that this extract is a potential active-ingredient in cosmetic and health products.
Acknowledgements: The authors are grateful for financial support from Naresuan University, the Center of Excellence for Innovation in Chemistry (PERCH-CIC), Office of the Higher Education Commission, Ministry of Education, and the Food and Drug Administration, Ministry of Public Health, Thailand. The first author was supported by a graduate scholarship for international journal publication from the Graduate School, Naresuan University.

\section{REFERENCES}

1. Mahajan SG, Mali RG, Mehta AA (2007) Protective effect of ethanolic extract of seeds of Moringa oleifera Lam. against inflammation associated with development of arthritis in rats. $J$ Immunotoxicol 4, 39-47.

2. Muangnoi C, Chingsuwanrote P, Praengamthanachoti P, Svasti S, Tuntipopipat S (2012) Moringa oleifera pod inhibits inflammatory mediator production by lipopolysaccharide-stimulated RAW 264.7 murine macrophage cell lines. Inflammation 35, 445-55.

3. Fard MT, Arulselvan P, Karthivashan G, Adam SK, Fakurazi S (2015) Bioactive extract from Moringa oleifera inhibits the pro-inflammatory mediators in lipopolysaccharide stimulated macrophages. Pharmacogn Mag 11, S556-63.

4. Siddhuraju P, Becker K (2003) Antioxidant properties of various solvent extracts of total phenolic constituents from three different agroclimatic origins of drumstick tree (Moringa oleifera Lam.) leaves. J Agr Food Chem 51, 2144-55.

5. Singh BN, Singh BR, Singh RL, Prakash D, Dhakarey R, Upadhyay G, Singh HB (2009) Oxidative DNA damage protective activity, antioxidant and antiquorum sensing potentials of Moringa oleifera. Food Chem Toxicol 47, 1109-16. 
6. Shih MC, Chang CM, Kang SM, Tsai ML (2011) Effect of different parts (leaf, stem and stalk) and seasons (summer and winter) on the chemical compositions and antioxidant activity of Moringa oleifera. Int $\mathrm{J} \mathrm{Mol}$ Sci 12, 6077-88.

7. Vieira GHF, Mourão JA, Ângelo AM, Costa RA, Vieira RHSF (2010) Antibacterial effect (in vitro) of Moringa oleifera and Annona muricata against Gram positive and Gram negative bacteria. Rev Inst Med Trop S Paulo 52, 129-32.

8. Peixoto JRO, Silva GC, Costa RA, Fontenelle JLS, Vieira GHF, Fonteles Filho AA, Vieira RHSF (2011) In vitro antibacterial effect of aqueous and ethanolic Moringa leaf extracts. Asian Pac J Trop Med 4, 201-4.

9. Galuppo M, de Nicola GR, Iori R, Dell'Utri P, Bramanti P, Mazzon E (2013) Antibacterial activity of glucomoringin bioactivated with myrosinase against two important pathogens affecting the health of longterm patients in hospitals. Molecules 18, 14340-8.

10. Rathi BS, Bodhankar SL, Baheti AM (2006) Evaluation of aqueous leaves extract of Moringa oleifera Linn for wound healing in albino rats. Indian $J$ Exp Biol 44, 898-901.

11. Muhammad AA, Pauzi NAS, Arulselvan P, Abas F, Fakurazi S (2013) In vitro wound healing potential and identification of bioactive compounds from Moringa oleifera Lam. BioMed Res Int 2013, 974580.

12. Gothai S, Arulselvan P, Tan WS, Fakurazi S (2016) Wound healing properties of ethyl acetate fraction of Moringa oleifera in normal human dermal fibroblasts. $J$ Intercult Ethnopharmacol 5, 1-6.

13. Ali A, Akhtar N, Chowdhary F (2014) Enhancement of human skin facial revitalization by moringa leaf extract cream. Postęp Dermatol Alergol 31, 71-6.

14. Kotani M, Matsumoto M, Fujita A, Higa S, Wang W, Suemura M, Kishimoto T, Tanaka T (2000) Persimmon leaf extract and astragalin inhibit development of dermatitis and IgE elevation in NC/Nga mice. J Allergy Clin Immunol 106, 159-66.

15. Kim MS, Kim SH (2011) Inhibitory effect of astragalin on expression of lipopolysaccharide-induced inflammatory mediators through NF- $\kappa \mathrm{B}$ in macrophages. Arch Pharm Res 34, 2101-7.

16. Soromou LW, Chen N, Jiang L, Huo M, Wei M, Chu X, Millimouno FM, Feng H, et al (2012) Astragalin attenuates lipopolysaccharide-induced inflammatory responses by down-regulating NF- $\kappa \mathrm{B}$ signaling pathway. Biochem Biophys Res Comm 419, 256-61.

17. Li F, Liang D, Yang Z, Wang T, Wang W, Song X, Guo M, Zhou E, et al (2013) Astragalin suppresses inflammatory responses via down-regulation of NF$\kappa \mathrm{B}$ signaling pathway in lipopolysaccharide-induced mastitis in a murine model. Int Immunopharmacol 17, 478-82.

18. Li F, Wang W, Cao Y, Liang D, Zhang W, Zhang Z, Jiang H, Guo M, Zhang N (2014) Inhibitory effects of astragalin on lipopolysaccharide-induced inflam- matory response in mouse mammary epithelial cells. J Surg Res 192, 573-81.

19. Han JT, Bang MH, Chun OK, Kim DO, Lee CY, Baek NI (2004) Flavonol glycosides from the aerial parts of Aceriphyllum rossii and their antioxidant activities. Arch Pharm Res 27, 390-5.

20. Choi J, Kang HJ, Kim SZ, Kwon TO, Jeong SI, Jang SI (2013) Antioxidant effect of astragalin isolated from the leaves of Morus alba L. against free radicalinduced oxidative hemolysis of human red blood cells. Arch Pharm Res 36, 912-7.

21. Luo C, Wang A, Wang X, Li J, Liu H, Wang M, Wang L, Lai D, Zhou L (2015) A new proline-containing flavonol glycoside from Caragana leucophloea Pojark. Nat Prod Res 29, 1811-9.

22. Faizi S, Siddiqui BS, Saleem R, Aftab K, Shaheen F, Gilani AH (1998) Hypotensive constituents from the pods of Moringa oleifera. Planta Med 64, 225-8.

23. Guevara AP, Vargas C, Sakurai H, Fujiwara Y, Hashimoto K, Maoka T, Kozuka M, Ito Y, et al (1999) An antitumor promoter from Moringa oleifera Lam. Mutat Res 440, 181-8.

24. Cheenpracha S, Park EJ, Yoshida WY, Barit C, Wall M, Pezzuto JM, Chang LC (2010) Potential antiinflammatory phenolic glycosides from the medicinal plant Moringa oleifera fruits. Bioorg Med Chem 18, 6598-602.

25. Waterman C, Cheng DM, Rojas-Silva P, Poulev A, Dreifus J, Lila MA, Raskin I (2014) Stable, water extractable isothiocyanates from Moringa oleifera leaves attenuate inflammation in vitro. Phytochemistry 103, 114-22.

26. Ayurvedic Pharmacopoeia Committee (2001) The Ayurvedic Pharmacopoeia of India, Government of India, New Delhi, pp 163-4.

27. Malaysian Herbal Monograph Committee (2013) Malaysian Herbal Monograph, Forest Research Institute Malaysia, Kuala Lumpur.

28. Zhang Y, Wade KL, Prestera T, Talalay P (1996) Quantitative determination of isothiocyanates, dithiocarbamates, carbon disulfide, and related thiocarbonyl compounds by cyclocondensation with 1,2-benzenedithiol. Anal Biochem 239, 160-7.

29. Tang L, Paonessa JD, Zhang Y, Ambrosone CB, McCann SE (2013) Total isothiocyanate yield from raw cruciferous vegetables commonly consumed in the United States. J Funct Foods 5, 1996-2001.

30. Qiao C, Han Q, Song J, Wang Z, Xu L, Xu H (2007) HPLC determination of two bioactive flavone glycosides and GC-MS analysis of volatile oil constituents in Alpinia nigra. Asian J Tradit Med 2, 85-91. 